\title{
Involvement of the Cerebral Monoamine Neurotransmitters System in Antidepressant-Like Effects of a Chinese Herbal Decoction, Baihe Dihuang Tang, in Mice Model
}

\author{
Meng-Li Chen, ${ }^{1}$ Jie Gao, ${ }^{2}$ Xin-Rong He, ${ }^{3}$ and Qian Chen ${ }^{1}$ \\ ${ }^{1}$ Department of Clinical Pharmacology, General Hospital of Peoples Liberation Army, Beijing 100853, China \\ ${ }^{2}$ Department of Pathology, General Hospital of Peoples Liberation Army, Beijing 100853, China \\ ${ }^{3}$ Traditional Chinese Medicine Dispensary, General Hospital of Peoples Liberation Army, Beijing 100853, China
}

Correspondence should be addressed to Qian Chen, chenqian@301hospital.com.cn

Received 26 April 2012; Accepted 8 June 2012

Academic Editor: Paul Siu-Po Ip

Copyright (C) 2012 Meng-Li Chen et al. This is an open access article distributed under the Creative Commons Attribution License, which permits unrestricted use, distribution, and reproduction in any medium, provided the original work is properly cited.

Baihe Dihuang Tang (BDT) is a renowned Chinese herbal formula which is commonly used for treating patients with mental instability, absentmindedness, insomnia, deficient dysphoria, and other psychological diseases. These major symptoms closely associated with the depressive disorders. BDT was widely popular use for treating emotion-thought disorders for many years in China. In the present study, the antidepressant-like effect of BDT in mice was investigated by using the forced swim test (FST) and the tail suspension test (TST). The underlying mechanism was explored by determining the effect of BDT on the level of cerebral monoamine neurotransmitters. BDT ( 9 and $18 \mathrm{~g} / \mathrm{kg}$, p.o. for 14 days) administration significantly reduced the immobility time in both the FST and the TST without changing locomotion in the open field-test (OFT). Moreover, BDT treatment at the dose of $18 \mathrm{~g} / \mathrm{kg}$ inhibited reserpine-induced ptosis. Meanwhile, BDT enhanced 5-HT and NA levels in mouse cerebrum as well as decreased the ratio of 5-HT compared to its metabolite, 5-HIAA, (turnover, 5-HIAA/5-HT) after TST. The results demonstrated that the antidepressant-like effect of BDT is mediated, at least partially, via the central monoaminergic neurotransmitter system.

\section{Introduction}

Depression is a mental illness that significantly affect a person's thoughts, behavior, feelings, and physical well-being and has become a major global psychiatric problem. In whole globe, approximately 450 million people suffer from depression or behavioral disorder. According to prediction, depression will become the second common disease by the year 2020 [1]. The classical antidepressants include the tricyclic antidepressant (TCA), monoamine oxidase inhibitor (MAOI), selective serotonin reuptake inhibitor (SSRI), noradrenergic reuptake inhibitor (NARI), and serotonin and noradrenaline reuptake inhibitor (SNRI) [2, 3]. Although these drugs show excellent efficacy, most of them frequently produce undesirable adverse effects. So it is urgent to explore more promising antidepressants for clinical needs of depressed patients.

Traditional herbal formulae have been clinically used for thousands of years in China. Nowadays, the use of traditional herbal formulae has provided us a prospective alternative in the treatment of depression $[4,5]$. Baihe Dihuang Tang (BDT) is a renowned Chinese herbal formula and firstly described in "synopsis of the Golden Chamber" (Jinkui Yaolue) written by Zhang Zhong Jing in the early 3th century. It is composed of two component herbs: lily bulb (Bulbus Lilii) and rehmannia root (Radix Rehmanniae). BDT is commonly used in folk for the therapeutic treatment of mental instability, absentmindedness, insomnia, deficient dysphoria, and other psychological diseases [6]. These major symptoms closely associated with the depressive disorders. 
BDT is widely popular use for treating emotion-thought disorders for many years in China. Some clinical studies have demonstrated antidepressant-like effects of BDT[7, 8]. Recently, pharmacological studies also have authenticated that plants of the BDT and some of their chemical constituents, including saponins, iridoids, and polysaccharides, displaying nervous system activities. Prepared Rehmannia, steamed roots of Rehmannia glutinosa, have effects on depression-like disorders, and antioxidation may be one of the mechanisms underlying its antidepressant action [9]. Catalpol, an iridoid glycoside, contained richly in Rehmannia, is found to be neuroprotective effect antioxidative ability, reduces cognitive impairment significantly [10-12] and therapeutic potential against inflammation-related neurodegenerative diseases [13]. As the component herbal drug, lily bulb or saponins from lily bulb also have depressant-like effects involved in the serotonergic system $[14,15]$ and the hypothalamic-pituitary-adrenal (HPA) axis in animal [16].

In the present study, we aim to investigate the antidepressant-like effects of BDT by using the forced swim and tail suspension tests in mice. The underlying mechanism of antidepression is explored by measuring the levels of monoamine neurotransmitters in mouse cerebrum.

\section{Materials and Methods}

2.1. Chemicals and Reagents. Desipramine, norepinephrine (NE), dopamine (DA), serotonin (5-HT), 8-O-acetylharpagide, and 5-hydroxyindoleacetic acid (5-HIAA) were obtained from Sigma-Aldrich (St. Louis, MO, USA). Reserpine injection $(1 \mathrm{mg} / \mathrm{mL})$ was produced by Guangdong Bangmin Pharmaceutical Co., Ltd. Ginsenoside Re, quercetin, was supplied by the State Drug Analysis Institute (Beijing, China). All other reagents and solvents used in the study were of analytical grade.

2.2. Plant Materials and Preparation of BDT. Bulbus Lilii (BL) and Radix Rehmanniae (RR) were purchased from Tongrentang Chinese Pharmaceutical Co. Ltd. (Beijing, China). The two herbs were ground into a coarse powder, respectively. BDT was formulated by mixing the two herbal powders in relative proportions according to a ratio of $2: 1$ (BL:RR). The herbal powder mixture was boiled in 8 volumes of water $(\mathrm{v} / \mathrm{w})$ in reflux for 60 minutes. The extraction procedure was repeated twice for 45 minutes. The pooled extract was filtered to remove debris. The concentrated extract was then dried by lyophilization to obtain the extract at a yield of $32.84 \%(\mathrm{w} / \mathrm{w})$. The extract was stored in the desiccator at $4^{\circ} \mathrm{C}$ until use. Contents of total saponins [17], total flavonoids [18], total iridoids [19], and total polysaccharides [20] in BDT extract were measured by modified methods, using ginsenoside Re, quercetin, 8acetylharpagide, and dextran as standards, respectively. The results indicated that BDT contained saponins, flavonoids, total iridoids, and total polysaccharides at concentrations of $0.91 \%, 0.52 \%, 0.66 \%$, and $4.36 \%(\mathrm{w} / \mathrm{w})$, respectively.

2.3. Animal and Treatment. Male ICR mice weighting 20$25 \mathrm{~g}$ were obtained from the Laboratory Animal Centre,
General Hospital of PLA, Beijing, China. The animals were maintained on a $12 \mathrm{~h}$ light/dark cycle under regulated temperature $\left(22 \pm 2^{\circ} \mathrm{C}\right)$ and humidity $(50 \pm 10 \%)$ and fed with standard diet and water ad libitum. They were allowed to acclimate three days before use. The experimental protocols for the present study have been approved by the Ethics Committee of the PLA General Hospital and were conducted in accordance with the Guide for the Care and Use of Laboratory Animals (China Ministry of Health). All experiments were performed between 09:30-14:00, and each animal was used only once.

The animals were randomly assigned into groups of 50 individuals. Distilled water was given to animals in group 1 (Vehicle group). Animals in group 2 were administered with positive compounds (Desipramine $20 \mathrm{mg} / \mathrm{kg}$ ). Animals in groups 3, 4, and 5 received intragastric doses of BDT extract powder at $4.5 \mathrm{~g}, 9 \mathrm{~g}$ and $18 \mathrm{~g} / \mathrm{kg}$, respectively. The drugs were given daily between 9:30 and 10:30 AM for 14 days. The test was conducted $2 \mathrm{~h}$ after the last treatment. The mice, after performing TST behavioral tests, were sacrificed for the determination of monoamine neurotransmitters.

2.4. Forced Swim Test (FST). The forced swim test was performed according to the method described by Porsolt et al. [21] with modifications. Briefly, mice were forced to swim in a transparent glass vessel $(25 \mathrm{~cm}$ in high $14 \mathrm{~cm}$ in diameter) filled with $10 \mathrm{~cm}$ of water at $24 \pm 2^{\circ} \mathrm{C}$. The total duration of immobility (seconds) was measured as described previously [22] during the last 4 minutes of a single 6minute test session. Mice were considered immobile when they ceased struggling and remained floating motionless in the water except the movements necessary to keep their heads above the water.

2.5. Tail Suspension Test (TST). Tail suspension test was carried out according to the method of Steru et al. [23]. Briefly, mice were suspended $5 \mathrm{~cm}$ above the floor by means of an adhesive tape placed approximately $1 \mathrm{~cm}$ from the tip of the tail. The total duration of immobility (s) was quantified during a test period of 6 minutes. Mice were considered immobile only when they hung passively.

2.6. Open-Field Test (OFT). The ambulatory behaviour was assessed in an open-field test as described previously [24, 25]. The open-field apparatus consisted of a square wooden arena $(40 \mathrm{~cm} \times 60 \mathrm{~cm} \times 50 \mathrm{~cm})$ with black surface covering the inside walls. The floor of the wooden arena was divided equally into 12 equal squares marked by black lines. Each mouse was placed individually into the center of the arena and allowed to explore freely. The number of squares crossed by the mouse and the number of rearings on the hind paws were recorded during a test period of 5 minutes. The arena floor was cleaned between the trials with a detergent, and the test was carried out in a temperature-, noise-, and lightcontrolled room.

2.7. Reversal of Reserpine-Induced Ptosis in Mice. The reserpine test was performed according to the method 
described by Bourin et al. [26] with modifications. Reserpine $(2.5 \mathrm{mg} / \mathrm{kg})$ was given intraperitoneally to the animals, and ptosis was evaluated 120 minutes after reserpine treatment. Animals were placed on a shelf $(20 \mathrm{~cm}$ above the tabletop) and the score of eyes ptosis was calculated as described previously [27], eyes open $=0$; one-quarter closed $=1$; half closed $=2$; three-quarters closed $=3$; completely closed $=4$.

2.8. Measurement of Monoamine Neurotransmitter Levels. To explore the detailed neurochemical mechanisms involved in the antidepressant-like effect of BDT, mice receiving BDT for 14 days were used for the determinations of NE, DA, 5-HT, and 5-HIAA (The metabolite of 5-HT) levels in the brain after TST. Mice were sacrificed by decapitation. Whole brains were rapidly removed from mice, weighted and frozen in liquid nitrogen immediately. The tissue samples were stored at $-80^{\circ} \mathrm{C}$ until assay. Samples were homogenized in 10 volumes of tissue lysis buffer $(0.6 \mathrm{mmol} / \mathrm{L}$ Perchloric acid, $0.5 \mathrm{mmol} / \mathrm{L} \mathrm{Na} 2 \mathrm{EDTA}$ and $0.1 \mathrm{~g} / \mathrm{L}$ L-Cysteine) centrifuged at $15,000 \mathrm{~g}$ for 15 minutes. The supernatant was mixed with equal volume of buffer $(1.2 \mathrm{~mol} / \mathrm{L} \mathrm{K} 2 \mathrm{HPO} 4,2.0 \mathrm{mmol} / \mathrm{L}$ Na2EDTA) and centrifuged at $15,000 \mathrm{~g}$ for 15 minutes. The resulting supernatant was used for assay. The contents of 5-HT, NA, DA, and 5-HIAA were measured as described previously using high-performance liquid chromatography (HPLC) with fluorescence detection with minor modifications [28]. The supernatant was analyzed by HPLC using an Alltech Alltima C18 column (particle size $5 \mathrm{~mm}, 4.6 \mathrm{~mm} \times$ $250 \mathrm{~mm}$ ). HPLC separation was achieved by an isocratic elution $(1 \mathrm{~mL} / \mathrm{min})$ with a mobile phase consisting of $87 \%$ buffer solution $(50 \mathrm{mmol} / \mathrm{L}$ citric acid, $50 \mathrm{mmol} / \mathrm{L}$ sodium acetate, $0.5 \mathrm{mmol} 1$-sodium heptanesulfonate, $5 \mathrm{mmol} / \mathrm{L}$ triethylamine, and $0.5 \mathrm{mmol} / \mathrm{L} \mathrm{Na2EDTA}, \mathrm{PH}=3.8)$ and $13 \%$ methanol $(\mathrm{v} / \mathrm{v})$. The eluate was monitored by fluorescence detector set at emission wavelength $280 \mathrm{~nm}$ and excitation wavelength $315 \mathrm{~nm}$. Calibration curve and limit of quantitation were listed (Table 2, Supplementary Material available online at doi:10.1155/2012/419257). The concentration of 5-HT, NE, DA, and 5-HIAA was estimated using a calibration curve of standard solution. The monoamine neurotransmitter levels was expressed as $\mu \mathrm{g} / \mathrm{g}$ wet weight of tissue.

2.9. Statistical Analysis. The results were expressed as mean \pm SEM. Multiple group comparisons were performed using one-way analysis of variance (ANOVA) followed by Dunnett's test in order to detect intergroup differences. A significant difference was determined when $P<0.05$.

\section{Results}

The FST and TST are the most widely used as behavioural tools for assessing antidepressant activity $[29,30]$. The results of BDT on the immobility duration in FST are demonstrated in Figure 1. Compared with the vehicle group, only BDT administration for 14 successive days at dose $18 \mathrm{~g} / \mathrm{kg}$ decreased the immobility time by $33.8 \%(P<0.05)$. The same treatment regimen with BDT at doses of 9 and $18 \mathrm{~g} / \mathrm{kg}$ also significantly decreased the immobility time in TST. The

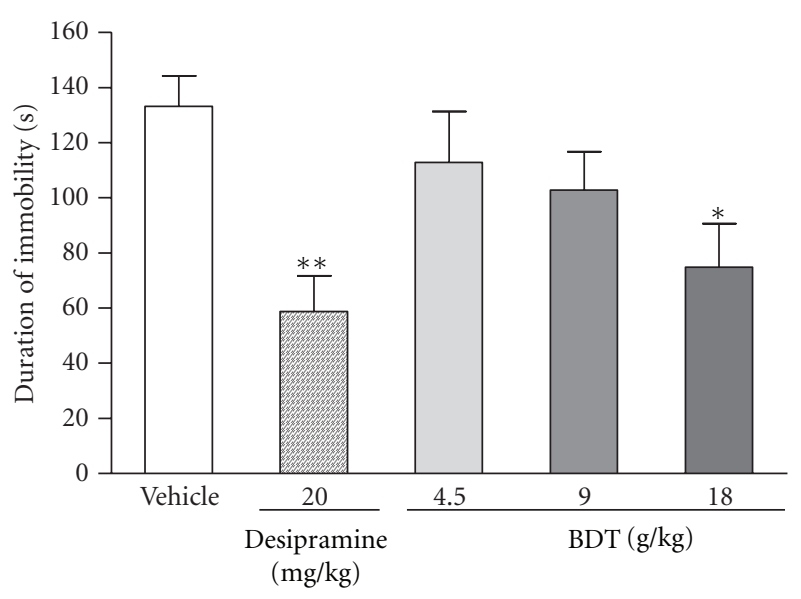

Figure 1: The effect of Baihe Dihuang Tang (BDT, 4.5, 9, $18 \mathrm{~g} / \mathrm{kg}$, p.o.) or desipramine $(20 \mathrm{mg} / \mathrm{kg}$, p.o.) on the immobility duration of in the forced swimming test. Values given are the mean $\pm \operatorname{SEM}(n=$ 10). ${ }^{*} P<0.05$ and ${ }^{* *} P<0.01$ as compared with vehicle group.

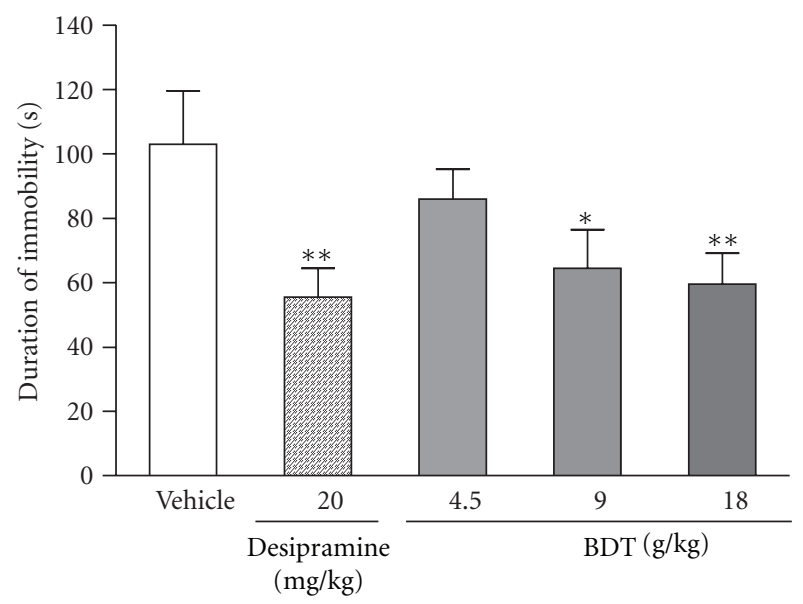

FIgure 2: The effect of Baihe Dihuang Tang (BDT, 4.5, 9, $18 \mathrm{~g} / \mathrm{kg}$, p.o.) or desipramine $(20 \mathrm{mg} / \mathrm{kg}$, p.o.) on the immobility duration of mice in tail suspension test. Values given are the mean $\pm \operatorname{SEM}(n=$ 10). ${ }^{*} P<0.05$ and ${ }^{* *} P<0.01$ as compared with vehicle group.

duration of immobility was reduced respectively by $37.3 \%$ and $42.2 \%$ when compared with the vehicle (Figure 2). Under the same experimental conditions, the similar effects were observed in mice treated with desipramine at a dose of $20 \mathrm{mg} / \mathrm{kg}$, which served as a positive control of the experiment. The reduction in the duration of immobility for mice given with desipramine was $55.9 \%$ and $46.1 \%$ in FST and TST, respectively (Figures 1 and 2).

As shown in Figure 3, BDT or desipramine administered for 14 successive days did not significantly affect the number of crossings and rearings in the open-field test (OFT) when compared with the vehicle group. It was an indication that the locomotor activity in mice OFT was not affected by the treatment of BDT or desipramine.

As shown in Figure 4, treating with BDT only at daily doses of $18 \mathrm{~g} / \mathrm{kg}$ for 14 days significantly antagonized 
TABLE 1: The effect of BDT on the monoamine neurotransmitter levels and 5-HIAA/5-HT turnover ratio in brain after mouse TST.

\begin{tabular}{|c|c|c|c|c|c|c|c|}
\hline \multirow{2}{*}{ Group } & \multirow{2}{*}{ Dose } & \multirow{2}{*}{ Ratio of brain/body (\%) } & \multicolumn{4}{|c|}{ Monoamine neurotransmitter level ( $\mu \mathrm{g} / \mathrm{g}$ wet tissue) } & \multirow{2}{*}{ 5-HIAA/5-HT } \\
\hline & & & NA & DA & $5-\mathrm{HT}$ & 5-HIAA & \\
\hline Normal & - & $1.16 \pm 0.024$ & $1.08 \pm 0.04$ & $1.21 \pm 0.05$ & $1.49 \pm 0.04$ & $0.48 \pm 0.05$ & $0.32 \pm 0.03$ \\
\hline Vehicle & - & $1.19 \pm 0.031$ & $0.77 \pm 0.07^{\# \#}$ & $0.97 \pm 0.09$ & $1.07 \pm 0.15^{\# \#}$ & $0.35 \pm 0.07$ & $0.32 \pm 0.02$ \\
\hline Desipramine (mg/kg) & 20 & $1.25 \pm 0.056$ & $1.15 \pm 0.03^{* *}$ & $1.01 \pm 0.03$ & $1.87 \pm 0.05^{* *}$ & $0.55 \pm 0.03$ & $0.29 \pm 0.01$ \\
\hline \multirow[t]{3}{*}{ BDT (g/kg) } & 4.5 & $1.18 \pm 0.025$ & $0.78 \pm 0.08$ & $1.04 \pm 0.02$ & $1.23 \pm 0.13$ & $0.39 \pm 0.09$ & $0.31 \pm 0.05$ \\
\hline & 9.0 & $1.26 \pm 0.071$ & $0.79 \pm 0.07$ & $1.01 \pm 0.05$ & $1.48 \pm 0.11^{*}$ & $0.42 \pm 0.05$ & $0.28 \pm 0.06$ \\
\hline & 18.0 & $1.21 \pm 0.053$ & $0.91 \pm 0.06^{*}$ & $1.02 \pm 0.07$ & $1.74 \pm 0.06^{* *}$ & $0.51 \pm 0.04^{*}$ & $0.25 \pm 0.02^{*}$ \\
\hline
\end{tabular}

Values were expressed as mean $\pm \operatorname{SEM}(n=10) .{ }^{\# \#} P<0.01$ as compared with the normal group. ${ }^{*} P<0.05$ and ${ }^{*} P<0.01$ as compared with the vehicle group.

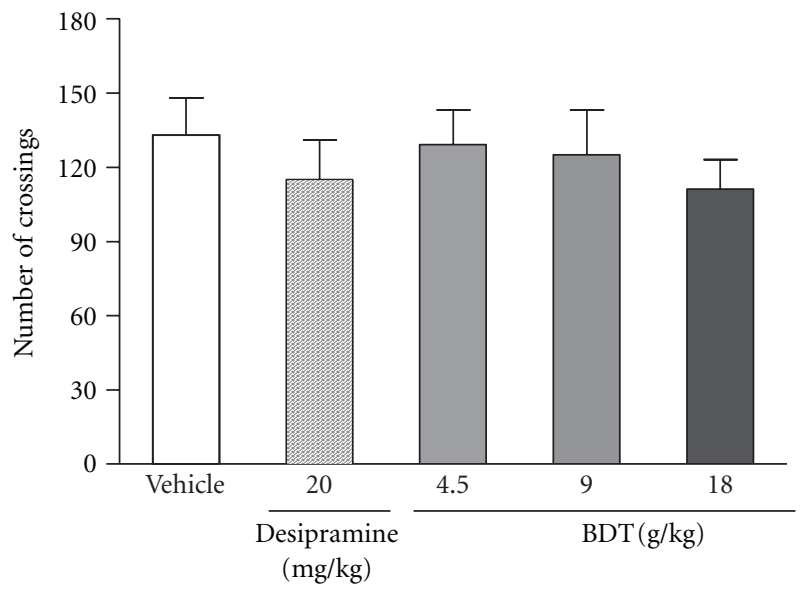

(a)

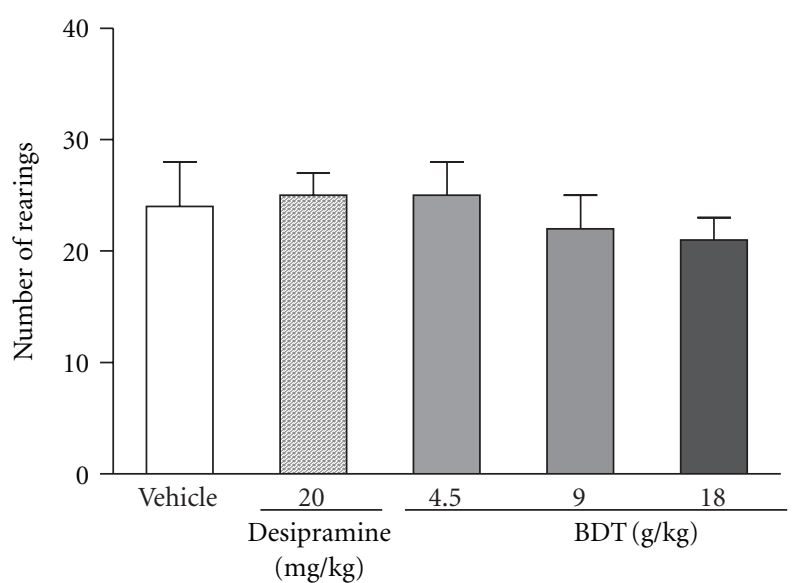

(b)

Figure 3: The effect of Baihe Dihuang Tang (BDT, 4.5, 9, $18 \mathrm{~g} / \mathrm{kg}$, p.o.) or desipramine ( $20 \mathrm{mg} / \mathrm{kg}$, p.o.) on the crossings (a) and rearings (b) in the open-field test in mice. Values given are the mean $\pm \operatorname{SEM}(n=10) .{ }^{*} P<0.05$ and ${ }^{* *} P<0.01$ as compared with vehicle group.

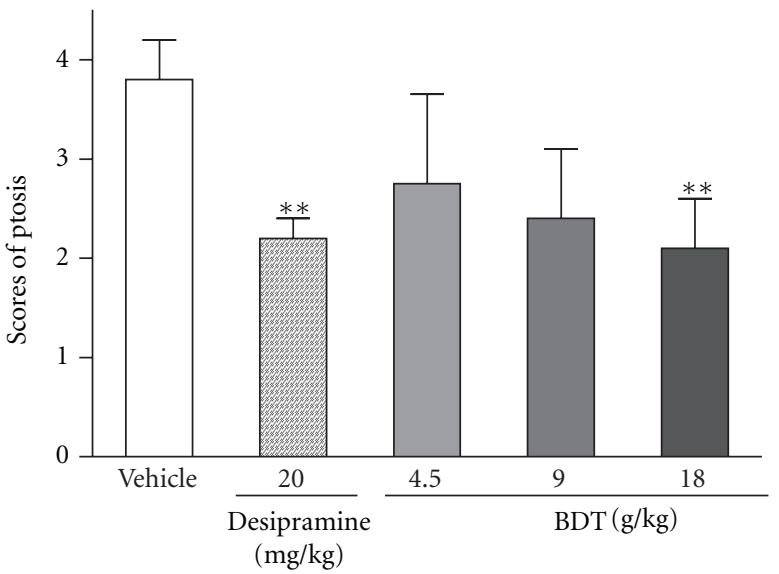

FIgure 4: The effect of Baihe Dihuang Tang (BDT, 4.5, 9, $18 \mathrm{~g} / \mathrm{kg}$, p.o.) or desipramine $(20 \mathrm{mg} / \mathrm{kg}$, p.o.) on reserpine-induced palpebral ptosis in mice. Values given are the mean $\pm \operatorname{SEM}(n=10)$. ${ }^{*} P<0.05$ and ${ }^{* *} P<0.01$ as compared with vehicle group.

ptosis induced by reserpine. The same treatment protocol using desipramine at $20 \mathrm{mg} / \mathrm{kg}$ also significantly antagonized reserpine-induced ptosis.
The data shows BDT has no effect on brain/body of mice (Table 1). The levels of NA, DA, 5-HT, and 5-HIAA in the brain of mice after TST were measured and recorded as shown in Table 1. Compared with normal group, the significantly decreased responses to the TST exposure on 5HT and NA levels were revealed in mice brain. BDT at 9 and $18 \mathrm{~g} / \mathrm{kg}$ significantly increased 5 -HT levels $(P<0.05$, $P<0.01$, resp.), while BDT at $18 \mathrm{~g} / \mathrm{kg}$ significantly elevated 5-HT metabolite, 5-HIAA, level $(P<0.05)$. NA level was significantly increased after treatment with the higher dose of BDT $(18 \mathrm{~g} / \mathrm{kg})$. As positive control, desipramine $(20 \mathrm{mg} / \mathrm{kg})$ produced an increase in the levels of monoamines 5-HT and NE. No significant changes in DA were observed in any treatment regimen after mice TST. The 5-HT turnover, as represented by the ratio of $5-\mathrm{HIAA} / 5-\mathrm{HT}$, was calculated. The significant difference in the 5-HT turnover were observed in group 5 received oral dose at $18 \mathrm{~g} / \mathrm{kg}$ of BDT $(P<0.05)$ (Table 1$)$.

\section{Discussion}

Forced swim test and tail suspension test are the widely used animal models of depression for the screening of antidepressive activity $[21,23]$. In these tests, animals are under stress from which they cannot escape in the confined 
space. After an initial period of struggling, they would become immobile. Such immobility represented a hopeless state similar to human mental depression and amenable to reversal by antidepressant drugs [21, 23]. In the present study, the antidepressive effects of BDT were assessed by using the two classical animal models. In addition, the effect of BDT on locomotion was evaluated by the OFT for excluding false-positive effects attributable to any psychostimulant effect of BDT. After treated with BDT at 9 and $18 \mathrm{~g} / \mathrm{kg}$ for 14 days, the mice showed a significant reduction of immobility time in both forced swim (Figure 1) and tail suspension tests (Figure 2). Moreover, BDT treatment did not increase the number of crossings and rearings (Figure 3 ). Our finding suggested that the reduction of immobility time elicited by BDT treatment in FST and TST was not related to a psychostimulant effect, but rather an antidepressant-like effect of BDT.

Depression has been associated with disturbances of brain monoamine neurotransmitters $[31,32]$. As inhibitor, reserpine can irreversibly inhibit the vesicular uptake of monoamines, including noradrenaline, dopamine and 5-hydroxytrytamine and its metabolites. Therefore, we explored the underlying antidepressive mechanism of BDT on the reserpine-induced animal depression model which is based on the monoamine hypothesis of depression [33]. Ptosis is observed as depletion of monoamines reserves or stimulation of monoamines reuptake $[34,35]$. In the reserpine-induced ptosis test, the results indicated that antidepressant-like effect of BDT may be involved in the preservation of monoamine neurotransmitters.

The dysfunction of the central nervous system involving the neurotransmitter 5-HT, NA, and DA has been suggested to play an important role in the pathogenesis of depression. For further evidence for antidepressant-like effect of BDT related to monoamine neurotransmitters, the contents of NE, DA, 5-HT, and 5-HIAA in brain were measured in TST. the TST is commonly used to detect and characterize the efficacy of antidepressant drugs and possesses greater sensitivity than the FST [36]. Our results show that BDT (9 and $18 \mathrm{mg} / \mathrm{kg}$ ) increased the 5-HT levels in a dose-dependent manner in mice brain. These effects were similar to those observed with the positive drug desipramine. As the ratio of neurotransmitter compared to its metabolites (turnover) can be used as an index of neurotransmitter metabolism, the reduction of turnover indicates a slowdown in the metabolism of neurotransmitters [37]. In present study, the decreased turnover (5-HIAA/5-HT) was observed, indicating a reduction in 5-HT metabolism. Our results suggest that BDT can cause serotonergic activation in the brain, which is consistent with the behavioral changes exhibited in TST. In parallel with the serotonergic system, the noradrenergic system is also important in depression and in mediating behavioral effects of antidepressant drugs [38]. NE level in brain of mice with BDT treatment also showed an increase after TST. The increase is consistent with the effect on reserpine-induced ptosis. Thus, the current study confirmed that the serotonergic system and noradrenergic system might be implicated in the antidepressant-like effect of BDT.
In conclusion, BDT possess antidepressant-like effect in the FST and TST in mice. The results demonstrated that the antidepressant-like effect of BDT is mediated, at least partially, via the central monoaminergic neurotransmitter system.

\section{Acknowledgments}

M. L. Chen and J. Gao contributed equally to this work. This study is supported in part by the National Natural Science foundation of China (no. 30973599).

\section{References}

[1] J. H. Kim, S. Y. Kim, S. Y. Lee, and C. G. Jang, "Antidepressantlike effects of Albizzia julibrissin in mice: Involvement of the $5-\mathrm{HT}_{1 \mathrm{~A}}$ receptor system," Pharmacology Biochemistry \& Behavior, vol. 87, no. 1, pp. 41-47, 2007.

[2] N. Bouvier, T. Trenque, and H. Millart, "Development of antidepressants drugs: experience and prospects," Presse Medicale, vol. 32, no. 11, pp. 519-522, 2003.

[3] C. B. Nemeroff, "Stress, menopause and vulnerability for psychiatric illness," Expert Review of Neurotherapeutics, vol. 7, supplement 1-3, no. 11, pp. S11-S13, 2007.

[4] Y. Z. Zhang, N. J. Yu, L. Yuan et al., "Antipressant effect of total flavonoids extracted from Xiaobuxing Tang in forced swimming test and learned helpness in rats and mice," Chinese Journal of Pharmcology and Toxicology, vol. 22, no. 1, pp. 1-8, 2008.

[5] G. K. Singh, D. Garabadu, A. V. Muruganandam, V. K. Joshi, and S. Krishnamurthy, "Antidepressant activity of Asparagus racemosus in rodent models," Pharmacology Biochemistry and Behavior, vol. 91, no. 3, pp. 283-290, 2009.

[6] H. W. Chen and S. F. Yin, "The progress on treatment of depression in TCM," Heilongjiang Journal of Traditional Chinese Medicine, vol. 40, no. 2, pp. 53-55, 2011.

[7] S. J. Quan, "Therapeutic effect of Baihe Dihuang Tang on the depressive patients," New Journal of Traditional Chinese Medicine, vol. 31, no. 2, pp. 16-17, 1999.

[8] W. Chen, S. H. Zhao, S. F. Xu et al., "Therapeutic effect of Baihe Dihuang Tang on the patients with post-stroke depression," Chinese Journal of Gerontology, vol. 24, no. 5, pp. 417-418, 2004.

[9] D. Zhang, X. S. Wen, X. Y. Wang, M. Shi, and Y. Zhao, "Antidepressant effect of Shudihuang on mice exposed to unpredictable chronic mild stress," Journal of Ethnopharmacology, vol. 123, no. 1, pp. 55-60, 2009.

[10] B. Jiang, J. H. Liu, Y. M. Bao, and L. J. An, "Catalpol inhibits apoptosis in hydrogen peroxide-induced PC12 cells by preventing cytochrome $\mathrm{c}$ release and inactivating of caspase cascade," Toxicon, vol. 43, no. 1, pp. 53-59, 2004.

[11] D. Q. Li, Y. L. Duan, Y. M. Bao, C. P. Liu, Y. Liu, and L. J. An, "Neuroprotection of catalpol in transient global ischemia in gerbils," Neuroscience Research, vol. 50, no. 2, pp. 169-177, 2004.

[12] D. Q. Li, Y. Li, Y. X. Liu, Y. M. Bao, B. Hu, and L. J. An, "Catalpol prevents the loss of CA1 hippocampal neurons and reduces working errors in gerbils after ischemia-reperfusion injury," Toxicon, vol. 46, no. 8, pp. 845-851, 2005.

[13] Y. Y. Tian, L. J. An, L. Jiang, Y. L. Duan, J. Chen, and B. Jiang, "Catalpol protects dopaminergic neurons from LPSinduced neurotoxicity in mesencephalic neuron-glia cultures," Life Sciences, vol. 80, no. 3, pp. 193-199, 2006. 
[14] L. L. Yin, C. A. Peng, Y. Zhang et al., "The expression of 5HT in brian treated with the Longshan lily, the famous-region drug, in chronic depression mice model," Lishizhen Medicine and Materia Medica Research, vol. 23, no. 2, pp. 357-358, 2012.

[15] Q. P. Guo, Y. Gao, and W. M. Li, "The depressive effect of active parts from lily on monoamine neurotransmitters in rat brian," Chinese Traditional Patent Medicine, vol. 31, no. 11, pp. 16691672, 2009.

[16] Q. P. Guo, Y. Gao, and W. M. Li, "Influence of the lilium saponins on HPA axis of the depression model rats," Chinese Pharmacological Bulletin, vol. 26, no. 5, pp. 699-700, 2010.

[17] S. Hiai, H. Oura, H. Hamanaka, and Y. Odaka, "A color reaction of panaxadiol with vanillin and sulfuric acid," Planta Medica, vol. 28, no. 2, pp. 131-138, 1975.

[18] C. C. Chang, M. H. Yang, H. M. Wen, and J. C. Chern, "Estimation of total flavonoid content in propolis by two complementary colometric methods," Journal of Food and Drug Analysis, vol. 10, no. 3, pp. 178-182, 2002.

[19] L. D. Kotenko, M. Y. Yakubova, N. A. Tselishcheva, M. T. Turakhozhaev, and T. A. Badalbaeva, "Quantitative determination of the total iridoids in plants of the genus Lagochilus," Chemistry of Natural Compounds, vol. 30, no. 6, pp. 669-672, 1994.

[20] X. G. Xi, X. L. Wei, Y. F. Wang, Q. Chu, and J. Xiao, "Determination of tea polysaccharides in Camellia sinensis by a modified phenol-sulfuric acid method," Archives of Biological Sciences, vol. 62, no. 3, pp. 669-676, 2010.

[21] R. D. Porsolt, A. Bertin, and M. Jalfre, "Behavioral despair in mice: a primary screening test for antidepressants," Archives Internationales de Pharmacodynamie et de Thérapie, vol. 229, no. 2, pp. 327-336, 1977.

[22] A. D. E. Zomkowski, A. O. Rosa, J. Lin, A. R. S. Santos, J. B. Calixto, and A. L. S. Rodrigues, "Evidence for serotonin receptor subtypes involvement in agmatine antidepressant like-effect in the mouse forced swimming test," Brain Research, vol. 1023, no. 2, pp. 253-263, 2004.

[23] L. Steru, R. Chermat, B. Thierry, and P. Simon, "The tail suspension test: a new method for screening antidepressants in mice," Psychopharmacology, vol. 85, no. 3, pp. 367-370, 1985.

[24] J. R. Royce, "On the construct validity of open-field measures," Psychological Bulletin, vol. 84, no. 6, pp. 1098-1106, 1977.

[25] A. D. E. Zomkowski, D. Engel, N. H. Gabilan, and A. L. S. Rodrigues, "Involvement of NMDA receptors and 1-argininenitric oxide-cyclic guanosine monophosphate pathway in the antidepressant-like effects of escitalopram in the forced swimming test," European Neuropsychopharmacology, vol. 20, no. 11, pp. 793-801, 2010.

[26] M. Bourin, M. Poncelet, R. Chermat, and P. Simon, "The value of the reserpine test in psychopharmacology," ArzneimittelForschung, vol. 33, no. 8, pp. 1173-1176, 1983.

[27] C. C. Sánchez-Mateo, C. X. Bonkanka, B. Prado, and R. M. Rabanal, "Antidepressant activity of some Hypericum reflexum L. fil. extracts in the forced swimming test in mice," Journal of Ethnopharmacology, vol. 112, no. 1, pp. 115-121, 2007.

[28] M. K. Lakshmana and T. R. Raju, "An isocratic assay for norepinephrine, dopamine, and 5- hydroxytryptamine using their native fluorescence by high-performance liquid chromatography with fluorescence detection in discrete brain areas of rat," Analytical Biochemistry, vol. 246, no. 2, pp. 166-170, 1997.

[29] J. F. Cryan, A. Markou, and I. Lucki, "Assessing antidepressant activity in rodents: recent developments and future needs,"
Trends in Pharmacological Sciences, vol. 23, no. 5, pp. 238-245, 2002.

[30] J. F. Cryan, C. Mombereau, and A. Vassout, "The tail suspension test as a model for assessing antidepressant activity: review of pharmacological and genetic studies in mice," Neuroscience and Biobehavioral Reviews, vol. 29, no. 4-5, pp. 571-625, 2005.

[31] D. J. Nutt, "Relationship of neurotransmitters to the symptoms of major depressive disorder," The Journal of Clinical Psychiatry, vol. 69, pp. 4-7, 2008.

[32] A. S. Elhwuegi, "Central monoamines and their role in major depression," Progress in Neuro-Psychopharmacology \& Biological Psychiatry, vol. 28, no. 3, pp. 435-451, 2004.

[33] Q. Q. Mao and Z. Huang, "Antidepressant drugs and animal models of depression," Foreign MedicalSciences, vol. 32, pp. 216-220, 2005.

[34] D. Dhingra and A. Sharma, "Antidepressant-like activity of Glycyrrhiza glabra L. in mouse models of immobility tests," Progress in Neuro-Psychopharmacology \& Biological Psychiatry, vol. 30, no. 3, pp. 449-454, 2006.

[35] M. Bourin, M. Poncelet, R. Chermat, and P. Simon, "The value of the reserpine test in psychopharmacology," ArzneimittelForschung, vol. 33, no. 8, pp. 1173-1176, 1983.

[36] J. Steru, R. Chermat, B. Thierry et al., "The automated tail suspension test: a computerized device which differentiates psychotropic drugs," Progress in Neuro-Psychopharmacology \& Biological Psychiatry, vol. 11, no. 6, pp. 659-671, 1987.

[37] M. Maes and H. Y. Meltzer, "The serotonin hypothesis of major depression," in Psychopharmacology: the 4th Generation of Progress, F. E. Bloom and D. J. Kupfer, Eds., pp. 933-944, Raven Press, New York, NY, USA.

[38] S. A. Montgomery, "Is there a role for a pure noradrenergic drug in the treatment of depression?" European Neuropsychopharmacology, vol. 7, no. 1, pp. S3-S9, 1997. 


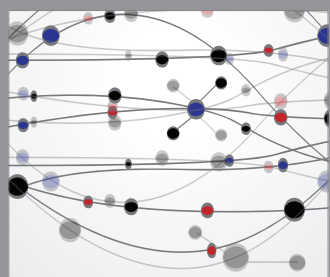

The Scientific World Journal
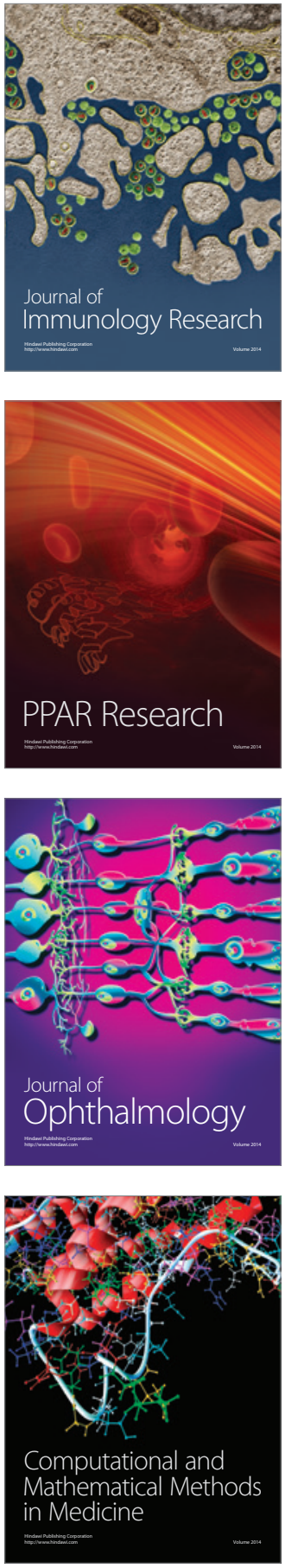

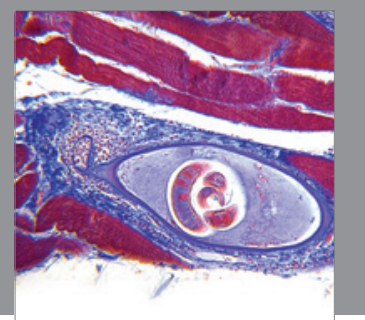

Gastroenterology

Research and Practice
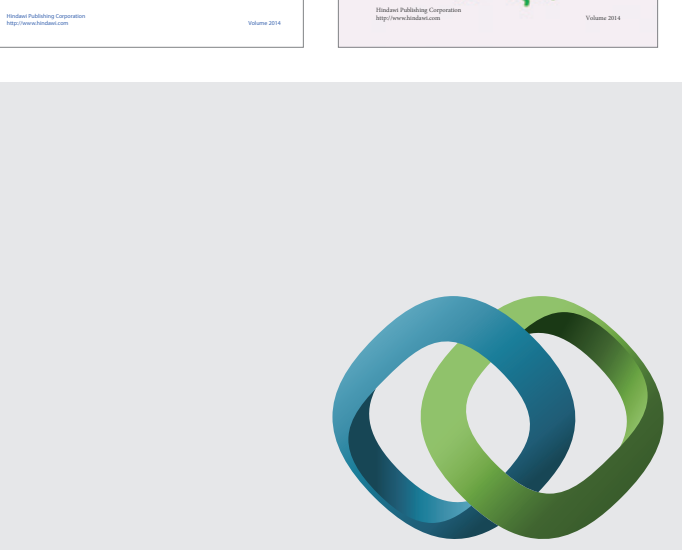

\section{Hindawi}

Submit your manuscripts at

http://www.hindawi.com
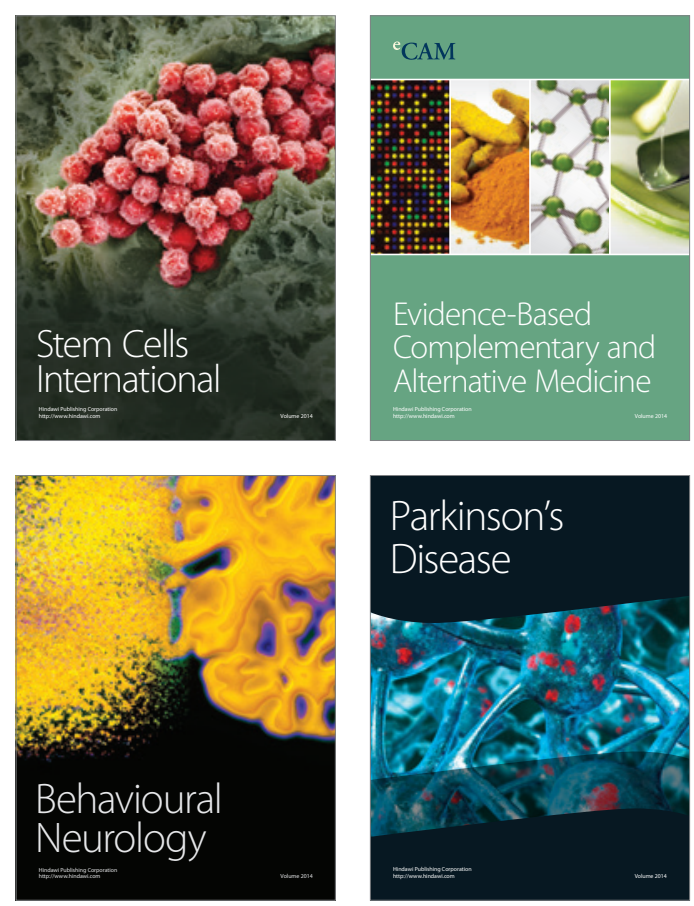

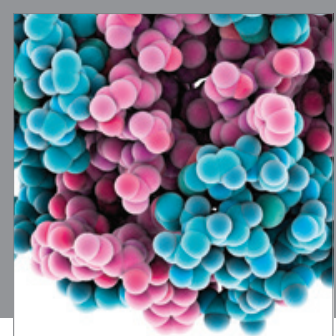

Journal of
Diabetes Research

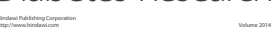

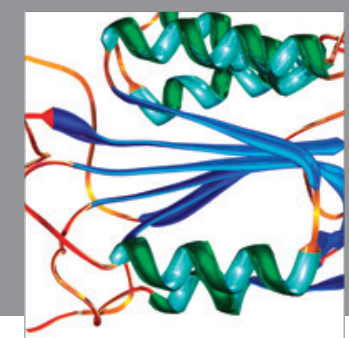

Disease Markers
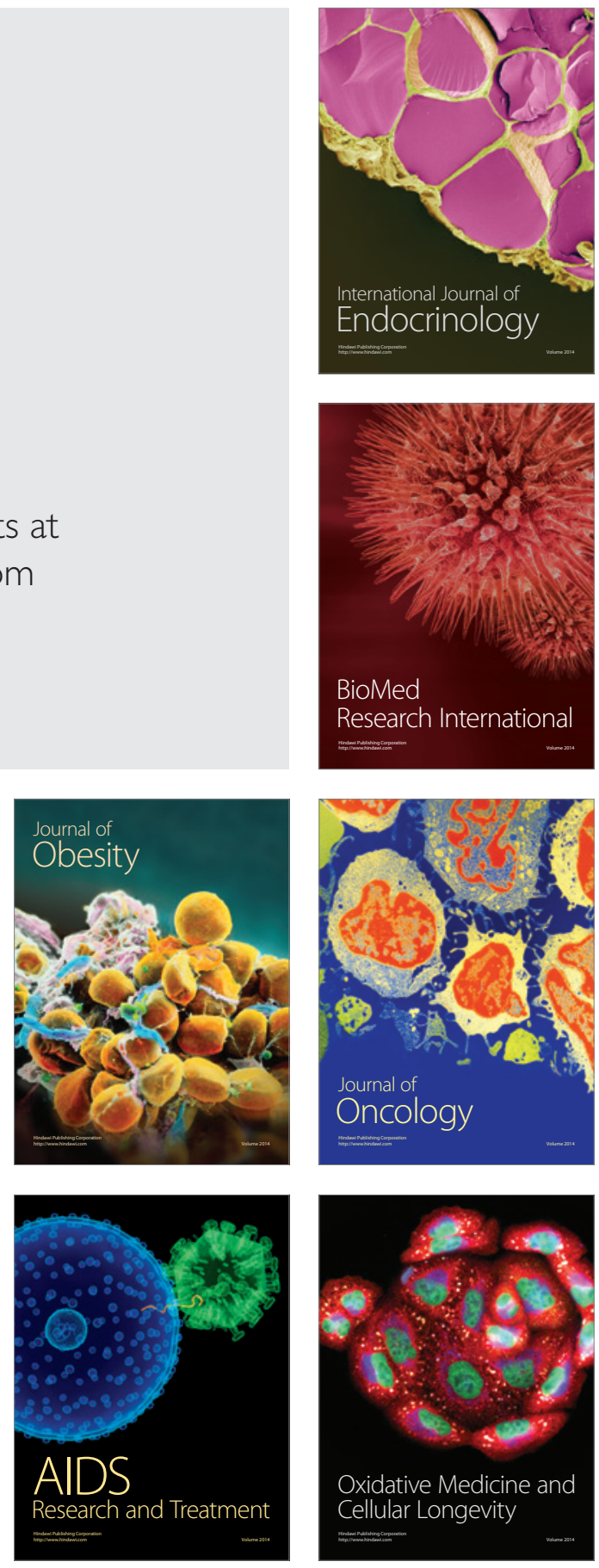